\title{
Wide Band Patch Antenna using Defect Ground Structure Optimizing by Genetic Algorithm
}

\author{
${ }^{1}$ Omar El Maleky, ${ }^{1}$ Farid Ben Abdelouahab, ${ }^{2}$ Mohammed Essaadi \\ ${ }^{1}$ Laboratory Materials and Radiation, Abdelmalek Essaadi University, Tetouan, Morocco \\ ${ }^{2}$ ENSIAS, Mohammed V Souissi University, Rabat, Morocco \\ o.elmaleky@gmail.com
}

\begin{abstract}
The patch antenna is widely used in our life for a lot of its strong points as a low cost, easy and simple fabricated structure, and a code characteristic in radiation profile. But the narrow bandwidth is, however, the main drawback of a microstrip patch antenna. In this paper the bandwidth of a patch antenna is improved by using a technique known as defected ground structure (DGS), and the size of the antenna is optimized using genetic algorithm. As a result, we were able to optimize the size of the initial antenna proposed $(50 \mathrm{~mm} * 30 \mathrm{~mm} * 1.55 \mathrm{~mm})$ and expand the bandwidth of the patch antenna. The final simulated prototype has a size of $26 \mathrm{~mm} * 20 \mathrm{~mm} * 1.55 \mathrm{~mm}$ which corresponds to a miniaturization rate equal to $76 \%$. In relation to the initial antenna, the antenna generates a bandwidth of $4.54 \mathrm{GHz}$, from $3.58 \mathrm{GHz}$ to $8.12 \mathrm{GHz}$, which means that the antenna covers the following technologies: WLAN Wireless Local Area Network, Radio local area Network, Worldwide Interoperability for Microwave Access Wimax, Hiper LAN2.
\end{abstract}

Keywords-; patch antenna; genetic algorithm; broadband; miniaturization; defect ground plan DGS.

\section{Introduction}

The patch antenna is a planar antenna whose radiating element is a generally square conductive surface separated from a conductive reflecting plane by a dielectric plate. Its production resembles a double-sided printed circuit, substrate, and is, therefore, favourable to industrial production. The antenna patch concept appeared in the 1950s, but true development only occurred in the 1970s. It can be used alone or as part of a network. Likewise, it can be integrated as close as possible to the electronic circuits by occupying a reduced volume and conforming to different types of surface. The major disadvantage of this type of antenna is the size which is an area of competition for antenna designers, and the bandwidth likewise. In this paper, we suggest using the DGS (defected ground plan) technique to widen the bandwidth as we use the genetic algorithm to optimize the parameters of the proposed antenna [1-8].

We have structured our article as follows: we will present the geometry of the initial antenna without DGS; then, we will introduce the different forms of DGS in the literature, and we will apply a DGS chosen among these different forms afterwards, and to miniaturize our structure we use the paradigm genetic algorithm, that is why we devoted a part to introduce this algorithm. We end our study with the simulations outcome. 


\section{Initial Geometry of Antenna}

\subsection{Patch antenna without defect ground structure}

The initial antenna proposed is shown in Figure 1. It is a simple structure with a partial ground plane; the antenna is printed on a Roger FR4 substrate of permittivity 4.4 with a loss tangent 0.02 , the length is 50 $\mathrm{mm}$, the width is $40 \mathrm{~mm}$ and the height is $1.6 \mathrm{~mm}$. Using microstrip line, we can give excitation to the antenna as shown in Figure1.
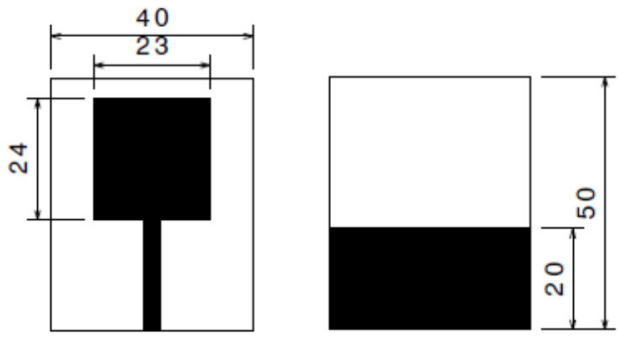

Figure 1. Initial patch antenna "A" without DGS.

The electromagnetic simulation software CST was used to study the performance of our structure. We used this simulator to assess the different radiation characteristics of our patch antenna, particularly the two parameters reflection coefficient and bandwidth.

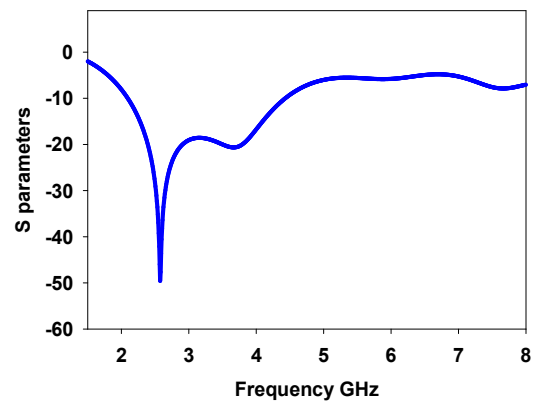

Figure 2 Reflection coefficient S11 parematers using CST without DGS

It is noted that the initially proposed antenna radiates in the band $2.04 \mathrm{GHz}-4.491 \mathrm{GHz}$, with good adaptation; the bandwidth covers the following technologies: ISM BANDS (2.4G Hz-2.5GHZ), WLAN Wireless Local Area Network (2.4GHz- 2.84GHz), BLUETOOTH $(2.402 \mathrm{GHz}$ and $2.480 \mathrm{GHz})$, or $(2.4 \mathrm{GHz}$ and $2.483 \mathrm{GHz}$ ) and almost the entire S-band $2.04 \mathrm{GHz}-4 \mathrm{GHz}$.

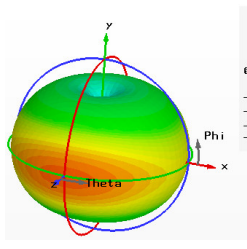

(a)

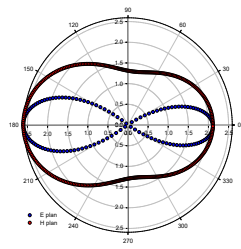

(b)

Figure 2 Simulation results of initial antenna ' $A$ ' without DGS : (a) 3D radiation pattern at 2.5 GHZ and (b) 2D radiation pattern at $2.5 \mathrm{GHz}$ patch antenna with defect ground structure 
The DGS structures are an evolution of electromagnetic bandgap structures (EBG: Electromagnetic BandGap) [5-6]. These EBG structures have aroused the interest of many researchers thanks to their interesting properties in terms of miniaturization and suppression of surface waves. The DGS structures offer the same advantages as the EBG structures with the difference that the use of one or a few cells is sufficient to ensure the same performances. A DGS unit cell consists of a defect (etching) in the ground plane of a transmission line in microstrip, in a coplanar waveguide or in any structure where a ground plane exists. There exist different forms of DGS such as: Dumbbell-shape, Spiral-shaped, H-shaped, Ushaped, arrowhead dumbbell, concentric ring-shaped, split-ring resonators, inter-digital, cross-shaped, circular head dumbbell, square heads connected with U slots, open loop dumbbell, fractal, half-circle, Vshaped, meander lines, $U$-head dumbbell, double equilateral $U$ and square slots connected with slot at edge [9].

We have chosen to introduce a double iteration of the DGS structure in the form of T in the ground plan of the patch Figure 3.
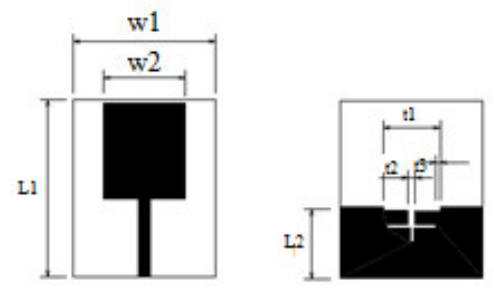

Figure 3 The initial patch antenna with DGS "antenna B"

Table 1 presents the parameters of the patch including the dimension of initial variable od DGS using in the optimization of the prototype $(L 1, L 2, W 1, W 2, t 1, t 2, t 3)$

Table 1 Initial parameter design antenna b 'with DGS'

\begin{tabular}{|c|c|}
\hline parameter & $\begin{array}{c}\text { Value } \\
(\text { mm })\end{array}$ \\
\hline $\mathrm{L} 1$ & 50 \\
\hline $\mathrm{W} 1$ & 40 \\
\hline $\mathrm{W} 2$ & 24 \\
\hline $\mathrm{T} 1$ & 16 \\
\hline $\mathrm{T} 2$ & 7 \\
\hline $\mathrm{T} 3$ & 1.2 \\
\hline $\mathrm{L} 2$ & 20 \\
\hline
\end{tabular}

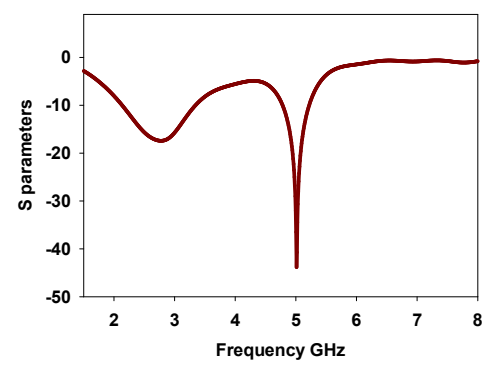

Figure 4 Reflection coefficient S11 parematers using CST with DGS 


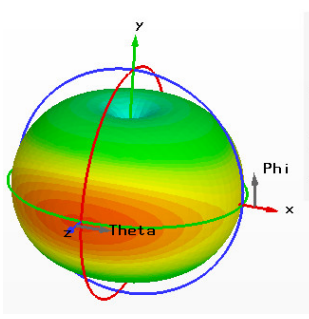

(a)
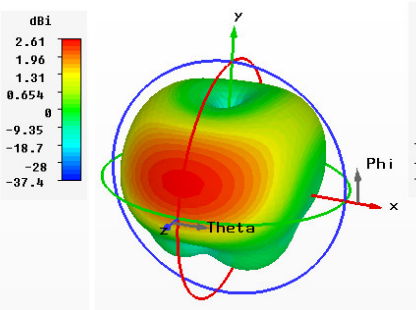

(b)

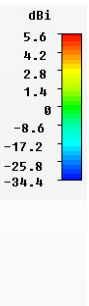

)

Figure 5 Simulation results of antenna 'B' with DGS : (a) 3D radiation pattern at $2.5 \mathrm{GHZ}$ and (b) 3D radiation pattern at $5 \mathrm{GHz}$

The simulation of return loss with the insertion of DGS shows the generation of another frequency from 4.7GHz to $5.3 \mathrm{GHz}$ (WiMAX technology). In the following part, the genetic algorithm is used to optimize the parameters $L 1, L 2, W 1, W 2, t 1, t 2$ and $t 3$, in order to miniaturize the size of the antenna and widen its bandwidth.

\section{Antenna Optimization using Genetic Algorithm}

\section{1 introduction to genetic algorithm}

Genetic algorithms are commonly used in multi-criteria optimizations [10-11]. This paradigm, combined with the terminology of genetics, allows us to exploit genetic algorithms: We find the notions of Population, Individual, Chromosome and Gene.

- $\quad$ The population is the set of possible solutions.

- The individual is a solution.

- Chromosome is a component of the solution.

- The gene is a characteristic, a particularity

The genetic algorithm aims to iteratively select the best sets of parameters that minimize the objective function in 3 steps [11-12].

- Selection: Selection involves selecting the most suitable individuals in order to have a population of solution closest to converging towards the overall optimum,

- $\quad$ Crossing: is the result obtained when two chromosomes share their characteristics. This allows the genetic brewing of the population and the application of the principle of heredity of Darwin's theory. There are two methods of cropping: single or double crossing.

- Mutation: to carry out a random mutation allowing the population evolution.

Figure 6 presents the block diagram of the genetic algorithm [13] 


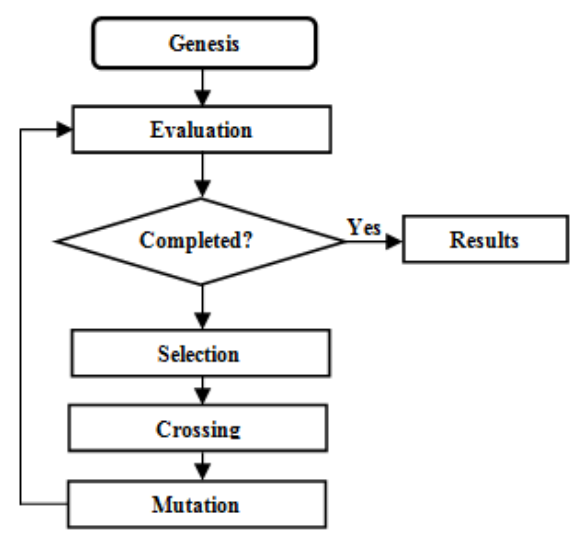

Figure 6 Block diagram of the genetic algorithm

\subsection{Optimization procedure : CST-Matlab}

We use the MATLAB software to implement the code of the genetic algorithm. The advantage of MATLAB is its power to call external programs. It is a powerful calculator for complex matrix manipulations. For antenna design and analysis, CST is equipped with a VBA script; the genetic algorithm is written under MATLAB calling a VBA script in CST which controls the analysis operations on CST Studio. The important process of the genetic algorithm used to optimize the major parameters of proposed antenna that can be summarized as follows:

- Name the different variables to optimize and define the maximum and minimum limits for each variable to be optimized.

- $\quad$ Population generation, each variable is an optimized chromosome. And write the variables (chromosomes) in line vector forms

- $\quad$ Each variable (each individual of chromosomes), a selection method is applied to select individuals with good characters.

- $\quad$ The selected individuals continue crossing and mutation.

- A new population is generated by continuous reproduction of the offspring. Repetition of evaluation (selection process, crossover, and mutation) until the criterion is satisfied.

The fitness function is defined as follows:

$$
\begin{aligned}
& \text { fitness: } \mathrm{P}(\mathrm{x})=\frac{1}{\mathrm{~N}} \sum_{\mathrm{fmin}}^{\mathrm{fmax}} \mathrm{P}(\mathrm{f}) \\
& \mathrm{P}(\mathrm{f})=\left\{\begin{array}{l}
S_{11} \text { for } S_{11} \geq-10 \\
-10 \text { f } \text { or } S_{11}<-10
\end{array}\right.
\end{aligned}
$$

S11 is the return loss:

$$
S 11=20 L O G\left|\frac{Z_{\text {in }}-Z_{c}}{Z_{\text {in }}+Z_{c}}\right|
$$

Where $Z_{\text {in }}$ is the input impedance of the antenna and $Z_{c}$ is the impedance characteristic of the microstrip line. 
FIG. 7 shows the flowchart of the genetic algorithm which presents the various steps summarized in two modules: a MATLAB module regrouping the MATLAB code and the other MODULE CST-VBA script

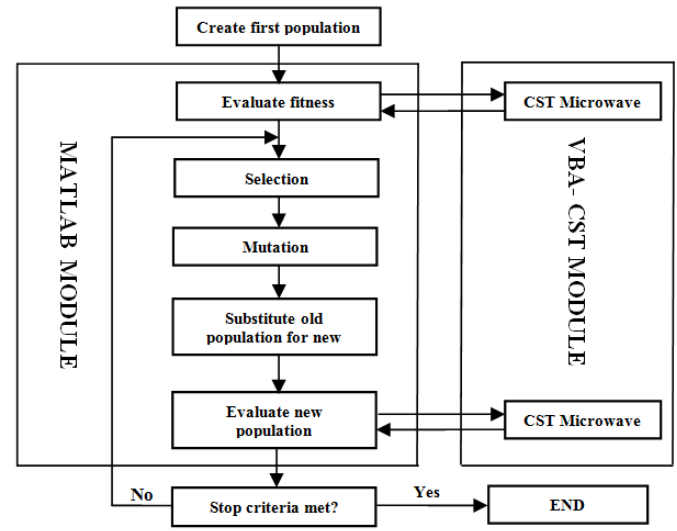

Figure 7 Genetic Algorithm block diagram

Table 2 Initial Parameter Design Antenna B ‘With DGS’ Optimizing Using Genetic Algorithm

\begin{tabular}{|c|l|}
\hline parameter & Value (mm) \\
\hline L1 & 26.00 \\
\hline W1 & 20.00 \\
\hline W2 & 10.00 \\
\hline T1 & 9.88 \\
\hline T2 & 6.10 \\
\hline T3 & 1.12 \\
\hline L2 & 20 \\
\hline L3 longth of patch & 13.09 \\
\hline
\end{tabular}

With these values, the performance of the optimal patch antenna with Defect ground structure is shown in Figure 9.

We can notice that the bandwidth becomes wide and that the optimized antenna covers the band Wimax wholly plus some technologies of the initial antenna. The new large band is " $3.58 \mathrm{GHz}$ to $8.12 \mathrm{GHz}$ ".

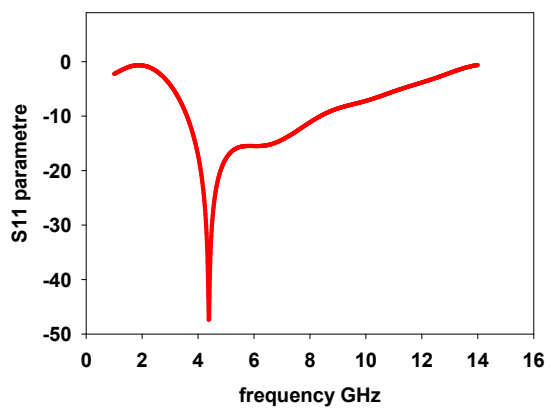

Figure 9 Reflection coefficient S11 with DGS and optimizing with genetic algorithm 


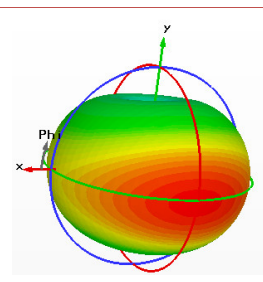

(a)

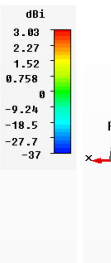

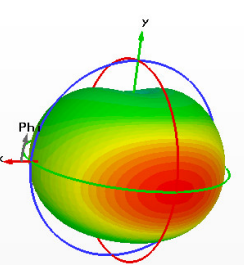

(b)

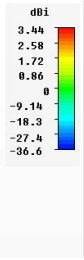

081
3.44
2.58
1.72
0.86
-98
-14
-18.3
-27.4
-36.6
-36

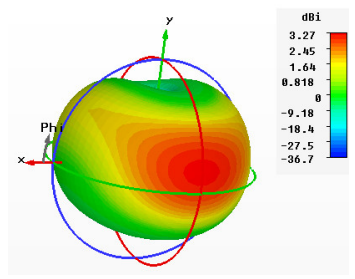

(c)

Figure 10 Simulation results of antenna ' $\mathrm{B}$ ' with DGS : (a) 3D radiation pattern at $5 \mathrm{GHZ}$ and (b) 3D radiation pattern at $7 \mathrm{GHz}$ and $(\mathrm{c}) 3 \mathrm{D}$ radiation pattern at $8 \mathrm{GHz}$

Table 3 Comparative Study

\begin{tabular}{|c|c|c|c|}
\hline \multirow{2}{*}{$\begin{array}{c}\text { Antennas } \\
\text { Table }\end{array}$} & \multicolumn{3}{|c|}{ Characteristics } \\
\hline & BW GHz & Technology & Size $(\mathrm{mm})$ \\
\hline $\begin{array}{c}\text { Without } \\
\text { DGS } \\
\text { Antenna } \\
\text { 'A' }\end{array}$ & $2.3-4.6$ & WIFI-Sband & $40 * 50$ \\
\hline $\begin{array}{c}\text { With DGS } \\
\text { Antenna } \\
\text { 'B' }\end{array}$ & $\begin{array}{c}2.3-3.7 \text { and } 4.7 \mathrm{GHz} \text { to } \\
5.3 \mathrm{GHz}\end{array}$ & $\begin{array}{l}\text { WIFI-Sband- } \\
\text { Wimax }\end{array}$ & $40 * 50$ \\
\hline $\begin{array}{c}\text { DGS-GA } \\
\text { Antenna } \\
\text { 'C' }\end{array}$ & $3.58-8.12$ & Wide band & $20 * 26$ \\
\hline
\end{tabular}

\section{Conclusion}

The genetic algorithm is used in this work to optimize the parameters of our prototype. The best results have been obtained, that is the miniaturization of the size of the initial patch antenna with a miniaturization rate equal to $76 \%$ and the widening of the bandwidth of the antenna to cover other technologies.

\section{REFERENCES}

[1] Ayoub, A. F. A., "Analysis of rectangular microstrip antennas with air substrates," Journal of Electromagnetic Waves and Applications, Vol. 17, No. 12, 1755-1766, 2003.

[2] Wong, K. L. and W. H. Hsu, "Abroad-band rectangular patch antenna with a pair of wide slits," IEEE Trans. Antennas Propagat., Vol. 49, No. 9, 1345-1347, September 2001.

[3] Yu, A. and X. X. Zhang, "A method to enhance the bandwidth of microstrip antennas using a modified Eshaped patch," Proceedings of Radio and Wireless Conference, 261-264, Aug. 10-13, 2003. 
Omar El Maleky, Farid Ben Abdelouahab, Mohammed Essaadi, Wide Band Patch Antenna using Defect Ground

Structure Optimizing by Genetic Algorithm. Transactions on Machine Learning and Artificial Intelligence, Vol 5 No 4 August (2017); p: 209-216

[4] Garg, B., R. Tiwari, A. Kumar, and S. K. Thakur, "Design of broadband rectangular microstrippatch antenna inset ' $L$ ' shaped feed with rectangular ' $L$ ' slots in ground plane," International Journal of Computer Applications, Vol. 29, No. 1, Sep. 2011, ISSN: 0975-8887.

[5] Xiao, J.-K. and W.-J. Zhu, "New bandstop filter using simple defected microstrip structure," Microwave Journal, Sep. 11, 2011.

[6] Ahn, D., J. S. Park, C. S. Kim, J. Kim, Y. Qian, and T. Itoh, "A design of the low-pass filter using the novel microstrip defected ground structure," IEEE Transactions on Microwave Theory and Techniques, Vol. 49, 86-93, Jan. 2001.

[7] Omar El Maleky, Farid Ben Abdelouahab, Mohamed Essaaidi, Laila Ajana "Reconfigurable T-Shaped Antenna for S-Band Applications" Proc. International Conference on Multimedia Computing and Systems Conf., October.2016

[8] Omar El Maleky, F. B. Abdelouahab, "Frequency Reconfigurable Patch Antenna for Wireless Communication", International journal of microwave and optical technology, Vol. 12, No.1, pp.45-51, January. 2017.

[9] Sung, Y. J., C. S. Ahn, and Y.-S. Kim, "Size reduction and harmonic suppression of rat-race hybrid coupler using defected ground structure," IEEE Microwave and Wireless Components Letters, Vol. 14, No. 1, 7-9, Jan. 2004.

[10] Y. Rahmat-Samii and E. Michielssen, Electromagnetic Optimization by Genetic Algorithms, Y. RahmatSamii and E. Michielssen, Eds. New York: Wiley, 1999.

[11] K. M. Luk, R. Chair, and K. F. Lee, "Small rectangular patch antenna," Electron. Lett., vol. 34, pp. 23662367, Dec. 1998.

[12] N. Herscovici, M. F. Osorio, and C. Peixeiro, "Minimization of a rectangular patch using genetic algorithms," in Proc. IEEE Antennas and Propagation Int. Symp., vol. 4, Boston, MA, July 2001, pp. 34-37.

[13] H. Choo, A. Hutani, L. C. Trintinalia, and H. Ling, "Shapeoptimization of broadband microstrip antennas using genetic algorithm,” Electron. Lett., vol. 36, pp. 2057-2058, Dec. 2000. 